\title{
Personal Identity and Persisting as Many*
}

\author{
Sara Weaver ${ }^{*}$ \\ John Turri a, b*
}

a Philosophy Department

University of Waterloo

200 University Avenue West

Waterloo, Ontario N2L3G1, Canada

sweaver@uwaterloo.ca

b Cognitive Science Program

University of Waterloo

200 University Avenue West

Waterloo, Ontario N2L3G1, Canada

john.turri@gmail.com

• Corresponding author

Abstract: Many philosophers hypothesize that our concept of personal identity is partly constituted by the one-person-one-place rule, which states that a person can only be in one place at a time. This hypothesis has been assumed by the most influential contemporary work on personal identity. In this paper, we report a series of studies testing whether the hypothesis is true. In these studies, people consistently judged that the same person existed in two different places at the same time. This result undermines some widely held philosophical assumptions, supports others, and fits well with recent discoveries on identity judgments about inanimate objects and non-human animals.

\footnotetext{
* This is the penultimate version of a paper forthcoming in T. Lombrozo, J. Knobe, \& S. Nichols (Eds.), Oxford Studies in Experimental Philosophy, Volume 2 (Oxford University Press). Please cite the final, published version if possible.
} 
Keywords: identity; thought experiments; social cognition

\section{Introduction}

Questions about personal identity have occupied center-stage in philosophy for several decades (e.g., Williams 1960; Wiggins 1967; Williams 1970; Parfit, 1971; Parfit 1984; Olson 1997, 2010; Shoemaker and Strawson 1999; McMahan 2002). The thought experiment is one important tool that philosophers have frequently used to investigate personal identity. These thought experiments often involve creative and unlikely scenarios. For instance, in one famous thought experiment, sometimes called the "transplant case," an individual's brain or "soul" is transplanted into a body different from the one they were born with (Locke 1689). Another famous thought experiment, due to Derek Parfit (1995), features an agent who enters a "teletransporter" on Earth. He presses a button, then the machine scans his body and sends the information to Mars, where another machine makes a perfect copy of his body with all the memories of the Earthly inhabitant.

Many researchers question the wisdom of basing our theories on such science fiction thought experiments. (e.g. Wilkes 1988; see also Fodor 1964, Gendler 2002). If you want to know what makes your heart a heart, there is no sense engaging in thought experiments. Rather, the sensible thing to do is to consult a textbook on human anatomy and physiology. If we want to know what makes a wolf a wolf, thought experimentation will not provide answers - biology 
will. Why would questions about persons be any different? In response, some philosophers defend the use of thought experiments on the grounds that they are not interested in "what the truth is" about personal identity. Instead, they are interested in "what we believe" about such cases (Parfit 1995: 15, 41) because this helps to reveal "the criteria of personal identity that we actually use" (Parfit 1971: 3). In other words, an important part of the philosophical discussion of personal identity has focused on facts about our ordinary judgments and concepts. How are the concepts constituted? What criteria do we apply when making judgments?

In this vein, philosophers have made some strong psychological claims about the criteria we apply when making judgments of personal identity — that is, about the "logic" of such judgments (Beck 2006: 33). It is widely hypothesized that our concept of personal identity is partly constituted by the one-person-one-place rule, an abstract rule stating that one and the same person cannot be in two different places at the same time. As it is sometimes put, personal identity cannot "branch" or be "one-to-many" across multiple bodies (e.g., Chisholm 1970; Chisholm 1997; Garrett 2002; Williams 1960; for reviews see Olson 2010 and Shoemaker 2010).

A famous thought experiment claimed to demonstrate the intuition that identity is one-toone is a variation of Derek Parfit's case of the "teletransporter," briefly mentioned above. Parfit asks us to image a scenario in which an agent, Derek, steps into an advanced scanner that "records [his] blueprint without destroying [his] brain and body" (Parfit 1984: 199). When Derek steps into the scanner, two figures step out of teletransportation devices, one from the same device on Earth and the other (which Parfit, somewhat tendentiously, calls his "Replica") from a 
different device on Mars. Regarding this case, Parfit comments,

Since I can talk to my Replica it seems clear that he is not me. Though he is exactly

like me, he is one person, and I am another. When I pinch myself, he feels nothing.

When I have my heart attack, he will again feel nothing. And when I am dead he will

live for another forty years. (Parfit 1984: 201)

Such a case, according to Parfit and others, reveals the counterintuitiveness of "branching identity."

Nevertheless, despite such claims about the centrality of the one-person-one-place rule, a careful review of the literature reveals at least some hesitation about it. Surprisingly, Parfit did not always take an unequivocal stance against the claim that the two figures could both be Derek. For instance, in his 1971 paper, Parfit concedes that it is not "absurd" that a mind could be "divided" into two streams of consciousness and thereby have "two simultaneous" streams of experience separate from one another. (Parfit thinks that this might actually happen in some cases where an epileptic elects to have a corpus callosotomy to eliminate unbearable seizures.) To make the point more vivid, Parfit considers another thought experiment about a math exam. Imagine that Parfit can easily and voluntarily "disconnect" and then "reconnect" the hemispheres of his brain. This divides and reunites his mind, creating two streams of consciousness that can, voluntarily, merge back into one. Suppose that Parfit is taking a difficult math exam. He identifies two possible strategies to solve the last problem. But he doesn't have enough time to try them both. Rather than hazard failure by selecting the wrong strategy, Parfit decides to divide 
his mind, work through each strategy in parallel, and then reunite his mind to record the correct answer. About such a case, Parfit claims, the natural thing to say is that both streams of thought were his.

But if "the criteria of personal identity that we actually use" (Parfit 1971: 3) countenance this verdict in the math-exam case, then in the double teletransporter case, why don't we say that both figures are Derek? Why don't we say that Derek is now experiencing two separate streams of consciousness, one on Earth and one on Mars? Because, Parfit answers, the cases differ in important ways. Parfit identifies two features of the math-exam case that "make us want to say that only one person was involved. The mind was soon reunited, and there was only one body." A case "where there are two bodies" is "over the borderline." After all, the two bodies "could live at opposite ends of the earth" and, thus, "it would become intolerable to deny that they were different people." This would defeat "the point of speaking of one person" (Parfit 1971: 7).

In this paper, we report a series of experiments that, for the first time, test the hypothesis that ordinary judgments of personal identity are committed to the one-person-one-place rule. Our investigation was motivated by an intrinsic interest in the topic and by results from recent psychological research on identity judgments about non-human animals and inanimate objects. More specifically, psychologists have found evidence that people do not follow a one-animalone-place rule, or a one-object-one-place rule. (See below for references.) This led us to wonder whether our judgments of personal identity would also violate the one-person-one-place rule.

Broadly speaking, such an investigation could ultimately support at least two different 
conclusions. On the one hand, it could turn out that people consistently reject simultaneous colocation in double-teletransportation cases. This would strongly support the philosophical hypothesis that the one-person-one-place is partly constitutive of our concept of personal identity. On the other hand, it could turn out that people consistently accept simultaneous colocation in such cases. This would suggest that the one-person-one-place rule is not part of the logic of the concept. Instead, it would suggest that Parfit's intuition about the math-exam case actually extends to cases of bodily duplication, and that bodily duplication does not tread "over the borderline" into an area where talk of personal identity becomes pointless or absurd. Moreover, it would suggest that judgments of personal identity might be importantly similar to other sorts of identity judgments, which psychologists have recently studied. (See below for more details.) In this way, reflection on judgments about philosophical thought experiments could promote progress in research on identity judgments in cognitive science.

To anticipate the results, we found that judgments of personal identity were not committed to a one-person-one-place rule. Instead, people consistently judged that one and the same person was in two different places at the same time. Moreover, people judged that a person continued existing in two different locations for an extended period time, up to at least a week, and while undergoing significantly different bodily changes at the two locations.

Our findings fit well with recent findings on judgments of identity for inanimate objects and non-human animals. Rips, Blok and Newman (2006) had adult participants imagine an animal that was put through a "duplicating device." The device produced two duplicates and then 
destroyed the original's matter. Many participants judged that both resulting objects were the original. Rips (2011) found similar results when adults were asked to imagine an iceberg that splits into two. Hood, Gjersoe and Bloom (2012) made similar findings with five and six year old children. Our research adds to these findings by demonstrating that they extend to adult judgments of personal identity. Overall, then, our findings suggest that judgments of personal identity are more similar to other sorts of identity judgments than one might initially suspect. More specifically, our findings suggest that these judgments recruit more basic criteria used to re-identify individual things and apply them to the domain of persons. Persons are no doubt special in many ways, perhaps most of all in the moral and legal rights they hold, and the criteria used to re-identify individuals seem to reflect such considerations (see especially Strohminger and Nichols 2014). But just as identity judgments generally do not follow a one-thing-one-place rule, personal identity judgments do not necessarily follow a one-person-one-place rule either.

\section{Preview of the Experiments}

We conducted six experiments. Experiment 1 elicited personal-identity judgments using a "quantum teletransportation" scenario based on famous thought experiments in the literature. The basic finding was that people judged that one person was located in two very distant places at the same time (Mars and Venus). By contrast, in a closely matched control, people did not judge that one person was in two different places at the same time. Experiments 2-6 address several natural questions that could be raised about the first experiment and, in the process, seek 
to replicate the basic finding and investigate its robustness. Experiment 2 tests whether the basic finding extends to another famous type of case from the literature, a "brain transplantation" scenario. Experiment 3 tests whether the basic finding is limited to scenarios that involve social cues and important personal relationships. Experiment 4 tests whether the basic finding is limited to scenarios where simultaneous co-location is fleeting, or whether it extends to cases involving prolonged co-location, up to a week. Experiment 5 tests whether the basic finding extends to scenarios that involve significantly different bodily changes in the two locations. Experiment 6 tests whether the basic finding persists when the scenarios are simplified and include explicit time-indexing.

\section{Experiment 1: Quantum Teletransportation}

\section{Method}

Participants. One hundred U.S. residents were tested (aged 19-65 years, mean age = 32 years; 96\% reporting English as a native language; 35 female). Participants were recruited and tested online using Amazon Mechanical Turk and Qualtrics and compensated $\$ 0.40$ for approximately 3 minutes of their time. Repeat participation was prevented. The same recruitment and compensation procedures were used for all subsequent experiments reported here.

Materials and Procedure. Participants were randomly assigned to one of two 
conditions, Single and Double, in a between-subjects design. Each participant read a single story about a man, Derek, living in a technologically advanced society of the future. Derek has a "Quantum Teletransporter" in house on Earth. In the Single condition, he says that he wants to visit his wife on Venus. In the Double condition, he says that he wants to visit his wife on Venus and his mother on Mars. In each condition, instantly a figure steps out of the teletransporter in Derek's wife's apartment on Venus, and she greets him happily. In the Double condition, a figure also instantly steps out of the teletransporter in Derek's mother's apartment on Mars, and she greets him happily. In the Single condition, instead of greeting a figure emerging from the teletransporter, Derek's mother happily greets a delivery person delivering her medication. In each condition, Derek's house on Earth is empty after he activates the teletransporter. The full text of the story is included in the Appendix.

Regarding the Teletransporter cases, Parfit assumes, (1) people believe that Derek survives on Venus in the single teletransporter case; (2) people don't believe that Derek survives on only Mars or only Venus in the double teletransporter case; and (3) people don't believe that Derek survives on both Mars and Venus in the double teletransporter case. Assumption 3 is an application of the one-person-one-place rule to the teletransporter case.

After reading the story, participants answered a series of questions corresponding to each of the assumptions. The first question was, "Which option best describes what happens in the story?" These were the options:

1. Derek hugged his wife but someone else hugged his mother. 
2. Derek hugged his mother but someone else hugged his wife.

3. Someone else hugged both Derek's wife and his mother.

4. Derek hugged his wife and Derek hugged his mother.

Participants then advanced to a new screen and were asked, "At the end of the story, where is Derek? Please check all that apply." These were the options:

1. He is on Venus.

2. He is on Earth.

3. He is on Mars.

4. He is nowhere.

Participants 1 in the Double condition then advanced to a new screen and rated their agreement with the statement, “At the end of the story, Derek's wife and Derek's mother both hug Derek, the same person who was just on Earth.” Responses were collected on a standard 6-point Likert scale anchored with "strongly disagree" (= 1), "disagree," "somewhat disagree," "somewhat agree," "agree," "strongly agree" (=6).

Questions were always asked in the same order and response options were rotated randomly, except for the elements of Likert scales, which were always presented in the same order. The story remained at the top of the screen throughout. Participants could not return to a previous screen to change their answers. Participants filled out a brief demographic survey after

1 For reasons related to Parfit's discussion, at this point we asked participants in all conditions to rate their agreement with the statement, "It is important that Derek's wife is hugging Derek, and not just someone very similar to Derek." However, at a reviewer's request, we omit this from the discussion. The same is true for Experiment 2. 
testing. These same basic procedures were used for all subsequent experiments reported here.

\section{Results}

Assignment to condition affected which option participants selected as best describing the situation, $\chi^{2}(3,100)=78.7, p<.001$, Cramer's $V=.887$. (See Figure 1.) Most participants in the Single condition $(86 \%)$ said that the best description was that Derek hugged his wife and someone else hugged his mother. Most participants in the Double condition $(70 \%)$ said that the best description was that Derek hugged both his wife and mother. Assignment to condition also affected where participants thought Derek was located at the end of the story, and these responses were consistent with which option participants thought best described the case: only one participant in Single (2\%) checked both "Venus" and "Mars," whereas twenty-eight (56\%) did so in Double, $\chi^{2}(1,100)=35.41, \mathrm{p}<.001$, Cramer's $\mathrm{V}=.595$. In the Double condition, participants tended to agree that Derek's wife and mother were hugging the same person, Derek, who was just on Earth $(\mathrm{M}=4.08, \mathrm{SD}=1.48), \mathrm{t}(49)=2.77, \mathrm{p}=.008, \mathrm{~d}=0.39$, test value $=3.5$. Most participants (70\%) agreed with this statement to at least some extent. 

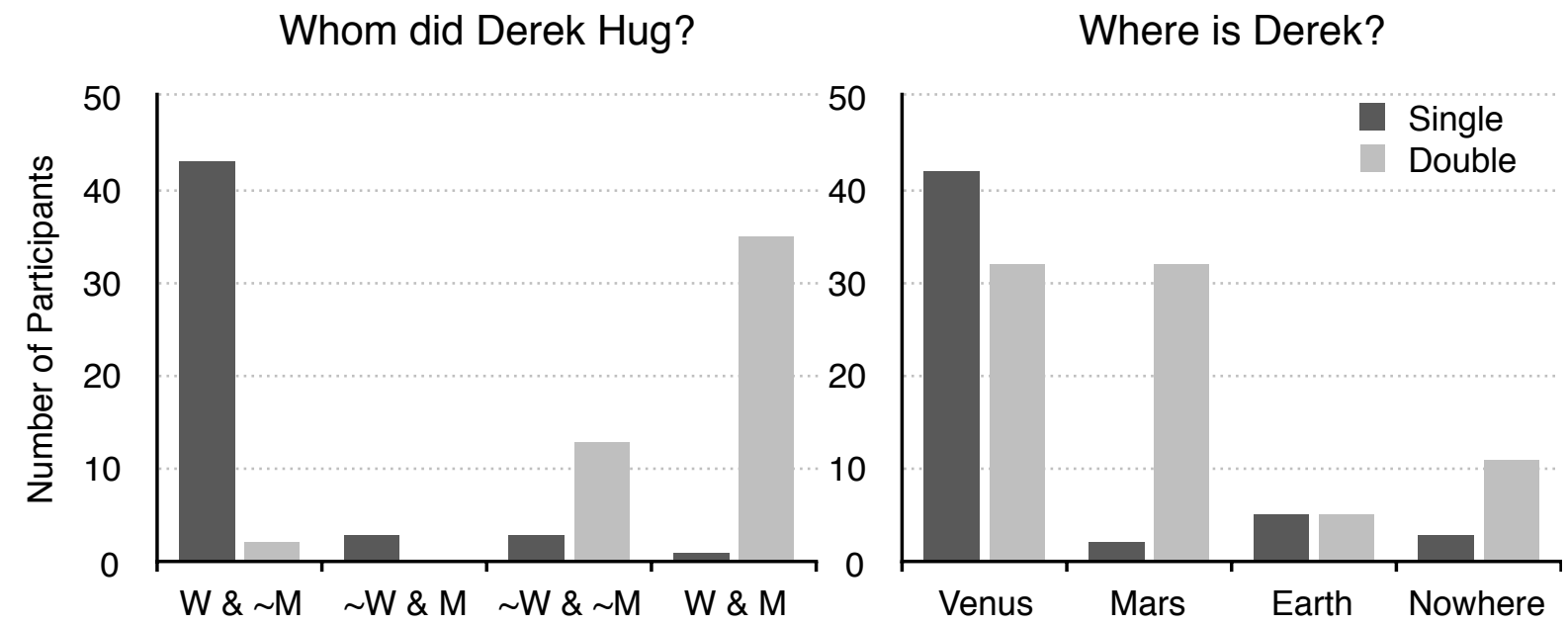

Figure 1. Experiment 1. Left Panel: the number of participants by condition (Single/Double) who selected each of the four options as the best description of what happened in the story. W \& $\sim$ M: Derek hugged his wife and someone else hugged his mother. $\sim \mathrm{W} \& \mathrm{M}$ : Derek hugged his mother but someone else hugged his wife. $\sim \mathrm{W} \& \sim \mathrm{M}$ : Someone else hugged both Derek's wife and his mother. W \& M: Derek hugged his wife and his mother. Right Panel: the number of participants by condition who answered that Derek's location at the end of the story was Venus, Mars, Earth, or nowhere. Participants were instructed to "check all that apply."

\section{Discussion}

The present study tested three assumptions about teletransportation cases: (1) people believe that Derek survives on Venus in the single teletransporter case; (2) people don't believe that Derek survives on only Mars or only Venus in the double teletransporter case; and (3) people don't believe that Derek survives on both Mars and Venus in the double teletransporter case. We found support for assumptions 1 and 2. Regarding assumption 1, most participants answered that Derek's location at the end of the single teletransporter case was Venus. Regarding assumption 2, very few participants answered that Derek survived on only Mars or only Venus in the double 
teletransporter case. However, we found evidence against assumption 3, which is an application of the one-person-one-place rule to the teletransportation case. The central tendency was to judge that Derek survives in both places in the double teletransporter case. We would not expect these results if people followed the one-person-one-place rule.

\section{Experiment 2: Brain Transplantation}

Two concerns might be raised about Experiment 1. First, many participants were likely familiar with science fiction entertainment, such as Star Trek, which involve teletransportation. Cooperative viewing of such fiction might train us to suspend our natural beliefs about the possibility of teletransportation or co-location, which could have influenced the results. Second, teletransportation can easily seem noninvasive - a simple scanning and transfer of information. If the procedure more straightforwardly or graphically compromised bodily integrity, then participants might judge the case differently. The present experiment addresses both of the worries by testing whether the same pattern of results generalizes to a case of brain transplantation.

\section{Method}

Participants. One hundred and one new participants were tested (aged 18-69 years, mean age $=$ 31 years; 93\% reporting English as a native language; 41 female). 
Materials and Procedure. Participants were randomly assigned to one of two conditions, Single and Double, in a between-subjects design. Each participant read a single story about a man, Derek, living in a technologically advanced society of the future. Derek's body suffers from a serious wasting condition, but his brain is perfectly healthy. So doctors suggest a procedure: grow a new body (or two) from Derek's DNA and transplant his brain into the new body (or bodies). In the story for the Single condition, half of Derek's brain is transplanted into a single host body, and the other half is kept in a preservation tank as a backup. The new body is then wheeled to the West Recovery room where Derek's wife waits. When the body awakens, the wife says, "My dear husband! I'm so happy to see you!" and the two hug. At the same time, in the East Recovery room where Derek's mother waits, Derek's daughter enters the room and greets her. The mother exclaims, "My dear granddaughter! I'm so happy to see you too!" (this is a control scenario). In the story for the Double condition, doctors grow two new bodies from Derek's DNA, and each new body is implanted with one half of Derek's brain. One new body is wheeled into the West Recovery room where Derek's wife waits, and the other is wheeled into the East Recovery room where Derek's mother waits. When the one body awakens, the wife says, "My dear husband! I'm so happy to see you!" and the two hug; when the other body awakens, the mother says, "My dear son! I'm so happy to see you!" and the two hug. The full text of the story is included in the Appendix.

After reading the story, participants answered a series of questions similar to Experiment 1. The first question was, "Which option best describes what happens in the story?" The options 
were the same four as in Experiment 1. Participants then advanced to a new screen and were asked, "At the end of the story, where is Derek? Please check all that apply." These were the options:

1. He is in the West Recovery Room.

2. He is in the East Recovery Room.

3. He is in the Operating Room.

4. He is nowhere.

Participants in the Double condition then advanced to a new screen and rated their agreement with the statement," "At the end of the story, Derek's wife and Derek's mother both hug Derek, the same person who just underwent a brain transplant procedure." Responses were collected on the same 6-point scale described in Experiment 1.

\section{Results}

Assignment to condition affected which option participants selected as best describing the situation, $\chi^{2}(3,101)=49.71, p<.001$, Cramer's $V=.702$. (See Figure 2.) Most participants in Single (74\%) said that the best description was that Derek hugged his wife and someone else hugged his mother. Most participants in Double (73\%) said that the best description was that Derek hugged both his wife and mother. Assignment to condition also affected where participants thought Derek was located at the end of the story, and these responses were consistent with which option participants thought best described the case: only three participants 
in Single (6\%) checked both "West Recovery Room" and "East Recovery Room," whereas twenty-six $(51 \%)$ did so in Double, $\chi^{2}(1,101)=24.96, \mathrm{p}<.001$, Cramer's V $=.497$. In the Double condition, mean agreement was non-significantly above the midpoint for the statement that Derek's wife and mother were both hugging Derek $(\mathrm{M}=3.82, \mathrm{SD}=1.62), \mathrm{t}(50)=1.43, \mathrm{p}=$. $16, d=0.20$. Most participants (69\%) agreed with this statement to at least some extent.

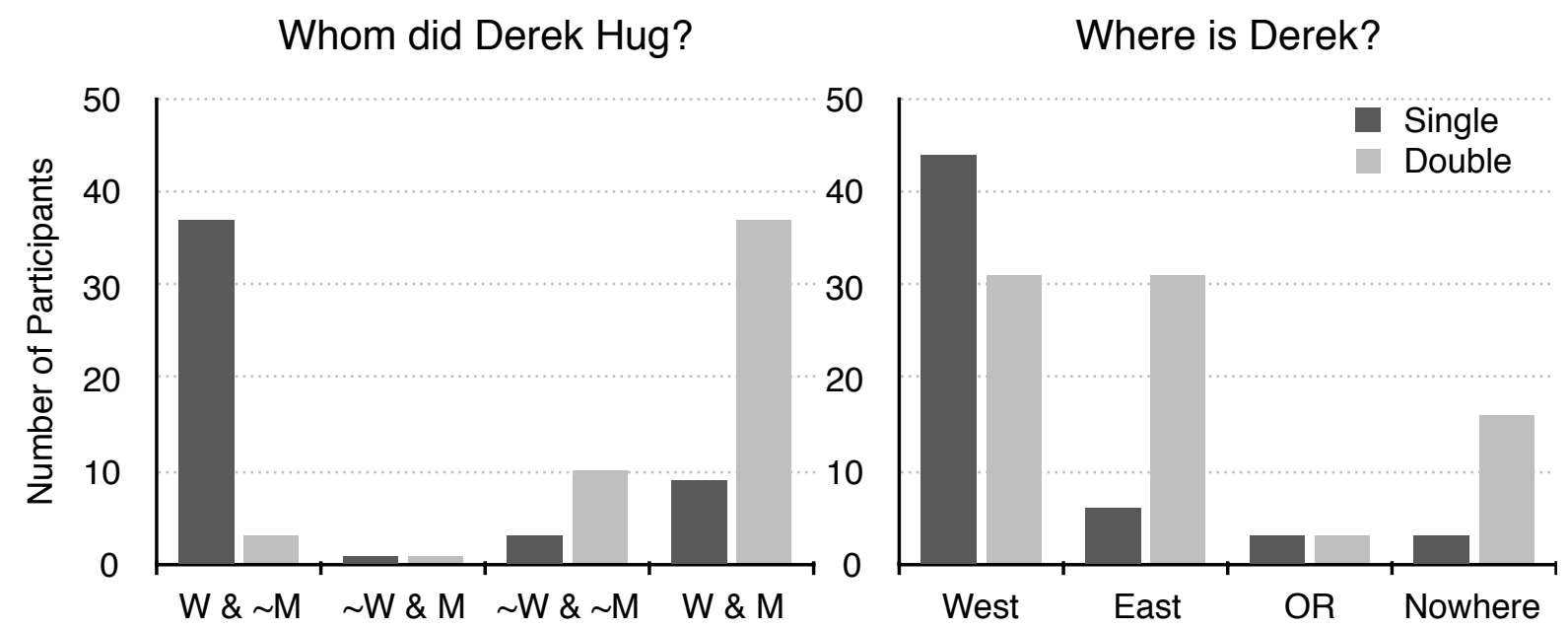

Figure 2. Experiment 2. Left Panel: the number of participants by condition (Single/Double) who selected each of the four options as the best description of what happened in the story. W \& $\sim \mathrm{M}$ : Derek hugged his wife and someone else hugged his mother. $\sim \mathrm{W} \& \mathrm{M}$ : Derek hugged his mother but someone else hugged his wife. $\sim \mathrm{W} \& \sim \mathrm{M}$ : Someone else hugged both Derek's wife and his mother. W \& M: Derek hugged his wife and his mother. Right Panel: the number of participants by condition who answered that Derek's location at the end of the story was the West Recovery Room (West), East Recovery Room (East), Operating Room (OR), and nowhere. Participants were instructed to "check all that apply."

\section{Discussion}

These results replicate the findings from Experiment 1. We tested three assumptions about brain 
transplant cases: (1) people believe that Derek survives in the West Recovery Room in the single transplant case; (2) people don't believe that Derek survives in only the West or East Recovery Room in the double transplant case; and (3) people don't believe that Derek survives in both the West and East Recovery Rooms in the double transplant case. We again found support for assumptions 1 and 2. Regarding assumption 1, most participants answered that Derek's location at the end of the single case was the West Recovery room. Regarding assumption 2, very few participants answered that Derek survived in only one of the recovery rooms in the double transplant case. However, we again found evidence against assumption 3, which is another instance of the one-person-one-place rule. The central tendency was to judge that Derek survives in both recovery rooms in the double transplant case. Again, we would not expect these results if people were strongly committed to the one-person-one-place rule.

\section{Experiment 3: Social Cues and Relationships}

Two concerns might be raised about both experiments thus far. First, the subject matter concerned close personal relationships (mother/son, wife/husband). The moral and emotional value attached to such relationships might have led many people to say that Derek was in both places because they wanted this to be true, even though they did not actually believe it was true. That is, perhaps the results were partly due to the unpleasantness of imagining Derek's wife or mother losing Derek. Second, characters in the story provided social cues suggesting that they 
thought Derek was in both places. This might have led many participants to defer to the characters' judgment and answer that Derek was in both places, even though they would not have reached that conclusion otherwise. The present experiment addresses both of the worries by comparing a case involving artifacts to one involving close personal relations, and by eliminating the social cues.

\section{Method}

Participants. One hundred and one new participants were tested (aged 18-69 years, mean age = 36 years; 97\% reporting English as a native language; 50 female).

Materials and Procedure. Participants were randomly assigned to one of two conditions, Clothes and Children, in a between-subjects design. Each participant read a single story about a man, Derek, similar to the story used in Experiment 1. In the story for each condition, Derek is on Earth, where he plans to attend a family reunion later in the day. But he left something in his apartment on Venus and something in his apartment on Mars. In the story for the Clothes condition, he left his favorite shirt on Venus and his favorite pants on Mars. In the story for the Children condition, he left his infant daughter on Venus and his infant son on Mars. The full text of the story is included in the Appendix.

After reading the story, participants answered a series of questions similar to Experiment 1. The first question was, "Which option best describes what happens in the story?" These were the options: 
5. Derek retrieved his [shirt/daughter] but someone else retrieved his [pants/son].

6. Derek retrieved his [pants/son] but someone else retrieved his [shirt/daughter].

7. Someone else retrieved Derek's [shirt and Derek's pants/daughter and Derek's son].

8. Derek retrieved his [shirt/daughter] and Derek retrieved his [pants/son].

Participants then advanced to a new screen and were asked, "At any point in the story, was Derek located in any of the following places?" Immediately below the question was a list of four places in a matrix table - Venus, Earth, Mars, and Jupiter — with Yes/No options for each. The places and answer options were rotated randomly.

\section{Results}

Assignment to condition did not affect which option participants selected as best describing the situation, $\chi^{2}(3,101)=1.78, p=.619$. Overall most participants $(78 \%)$ said that the best description was that Derek recovered the object on Venus and the object on Mars. (See Figure 3.) A small minority (18\%) said that someone else recovered both objects. Assignment to condition did not affect how frequently participants placed Derek on both Mars and Venus, $\chi^{2}(1,101)=$ $1.75, \mathrm{p}=.212$. Overall eighty-two participants (81\%) placed Derek on both Mars and Venus. 

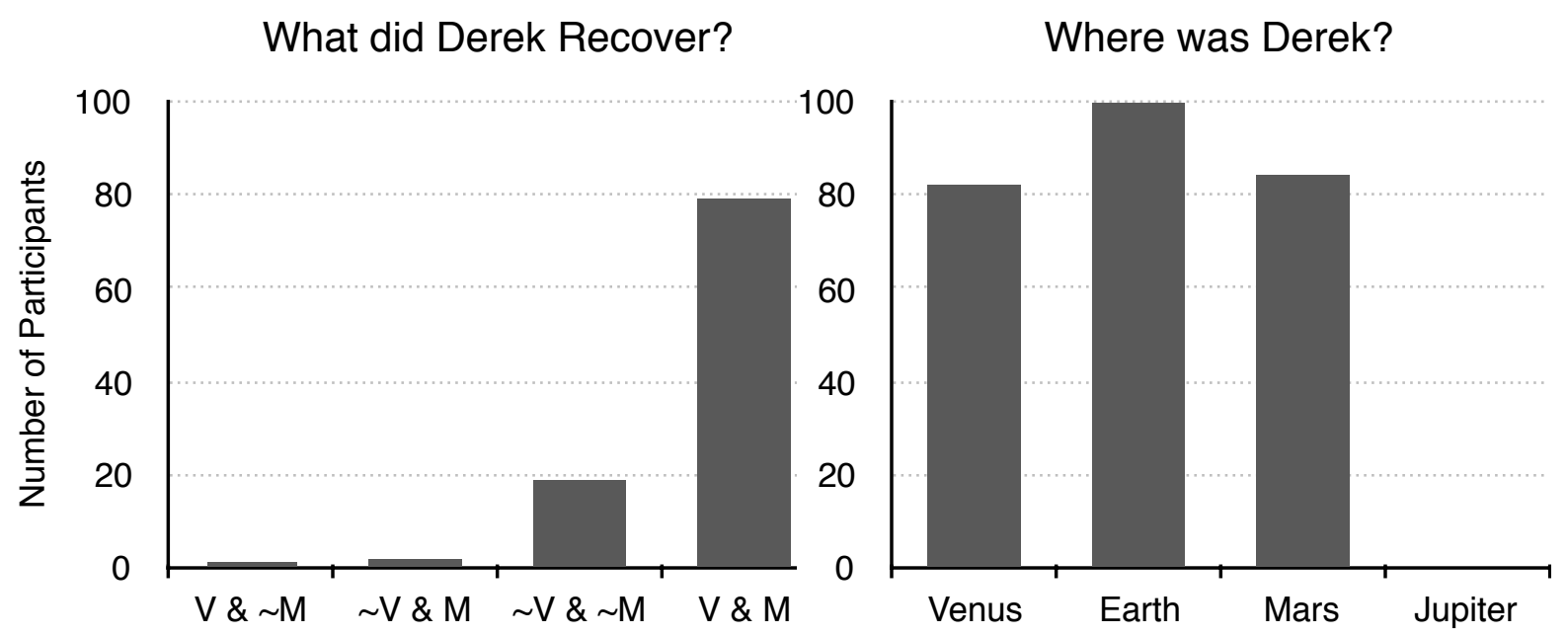

Figure 3. Experiment 3. Left Panel: the number of participants who selected each of the four options as the best description of what happened in the story. $\mathrm{V} \& \sim \mathrm{M}$ : Derek recovered the object on Venus but someone else recovered the object on Mars. $\sim \mathrm{V} \& \mathrm{M}$ : Derek recovered the object on Mars but someone else recovered the object on Venus. $\sim \mathrm{V} \& \sim \mathrm{M}$ : Someone else recovered the object on Venus and on Mars. V \& M: Derek recovered the object on Venus and on Mars. Right Panel: the number of participants by condition who answered that Derek's was in the various locations at some point in the story. Each panel collapses across condition (clothing/ children).

\section{Discussion}

These results replicate and generalize the findings from Experiments 1 and 2. Most participants agreed that Derek recovered objects on different planets at the same time. Again, we would not expect these results if people were strongly committed to the one-person-one-place rule or viewed survival in both places as counterintuitive or contradictory. Moreover, we observed no difference between a case involving close personal relationships (a man and his children) and a 
case involving no personal relationships (a man and his clothes).

\section{Experiment 4: Time Lapse}

The results thus far suggest that people do not follow the one-person-one-place rule when making judgments of personal identity. However, people might not tolerate simultaneous colocation for long. More specifically, although people accept that one person can be located in two different places at the same time, they might doubt that co-location can persist for more than a very short period of time. For example, although people might think that Derek can exist simultaneously on Venus and Mars for a few seconds - enough for him to dash out of the teletransporter, grab a garment, then beam back to Earth — they might deny that Derek could exist in both places for, say, an hour or a week. The present experiment tested this concern by presenting participants with cases of simultaneous co-location that take place over periods of a second, an hour, and a week.

\section{Method}

Participants. One hundred and fifty-four new participants were tested (aged 19-63 years, mean age $=32$ years; 94\% reporting English as a native language; 49 female).

Materials and Procedure. Participants were randomly assigned to one of three conditions (Second, Hour, Week) in a between-subjects design. Each participant read a single story about a man, Derek, similar to the story used for the Clothes condition in Experiment 3. 
The key difference this time is that the stories for the different conditions varied how much time the teletransported figures spent on the respective planets. In the story for the Second condition, after Derek teletransports from Earth, the man who emerges from the transporter on Venus is hurried and rests for one second before retrieving the garment and re-entering the teletransporter; the same is true for the man on Mars. In the story for the Hour condition, in each place the man who emerges is tired and rests for an hour. The story for the Week condition is the same except that the interval is a week. The full text for all stories is included in the Appendix.

After reading the story, participants answered the same questions as in Experiment 3. Following these questions, participants advanced to a new screen and rated their agreement with the following statement:

The same person retrieved the shirt and the pants.

Responses were collected on a standard 6-point Likert scale, 1 ("strongly disagree") - 6 (“strongly agree”).

\section{Results}

Assignment to condition did not affect which option participants selected as best describing the situation, $\chi^{2}(6,154)=5.18, p=.521$. Overall most participants $(80 \%)$ said that the best description was that Derek recovered the object on Venus and the object on Mars. (See Figure 4.) A small minority (14\%) said that someone else recovered both objects. Assignment to condition did not affect how frequently participants placed Derek on both Mars and Venus (i.e. answered 
"yes" for both the "Mars" and "Venus" options), $\chi^{2}(2,154)=0.18, p=.913$. Overall one hundred nineteen participants (77\%) placed Derek on both Mars and Venus. Assignment to condition did not affect mean agreement with the statement, "The same person retrieved the shirt and the pants," $\mathrm{F}(2,151)=0.13, \mathrm{p}=.880$. Overall mean agreement $(\mathrm{M}=4.64, \mathrm{SD}=1.39)$ was significantly above the neutral midpoint, $\mathrm{t}(153)=10.17, \mathrm{p}<.001, \mathrm{~d}=0.82$, test value $=3.5$. (See Figure 5.) Most participants (82\%) agreed with this statement to at least some extent.
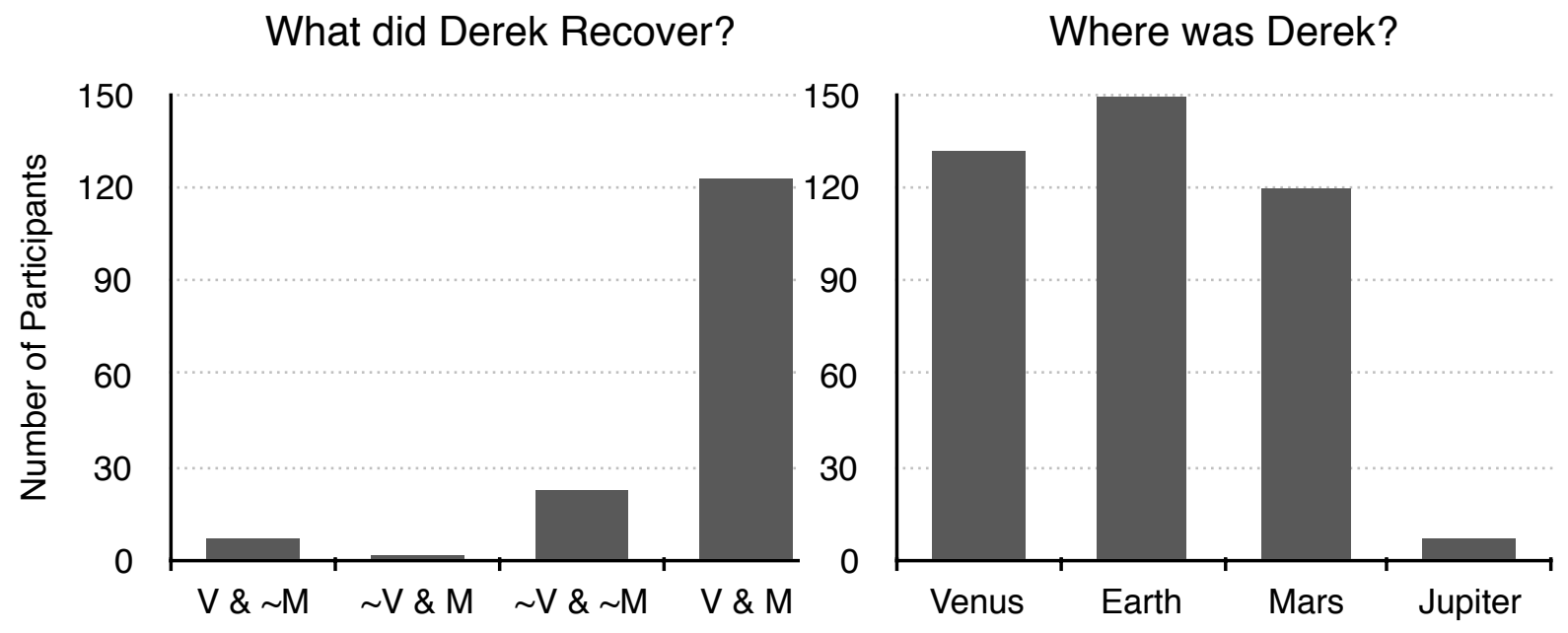

Figure 4. Experiment 4. Left Panel: the number of participants who selected each of the four options as the best description of what happened in the story. V \& M: Derek recovered the object on Venus but someone else recovered the object on Mars. $\sim \mathrm{V} \& \mathrm{M}$ : Derek recovered the object on Mars but someone else recovered the object on Venus. $\sim \mathrm{V} \& \sim \mathrm{M}$ : Someone else recovered the object on Venus and on Mars. V \& M: Derek recovered the object on Venus and on Mars. Right Panel: the number of participants placing Derek in the various locations at some point in the story. Each panel collapses across condition (second/hour/week). 

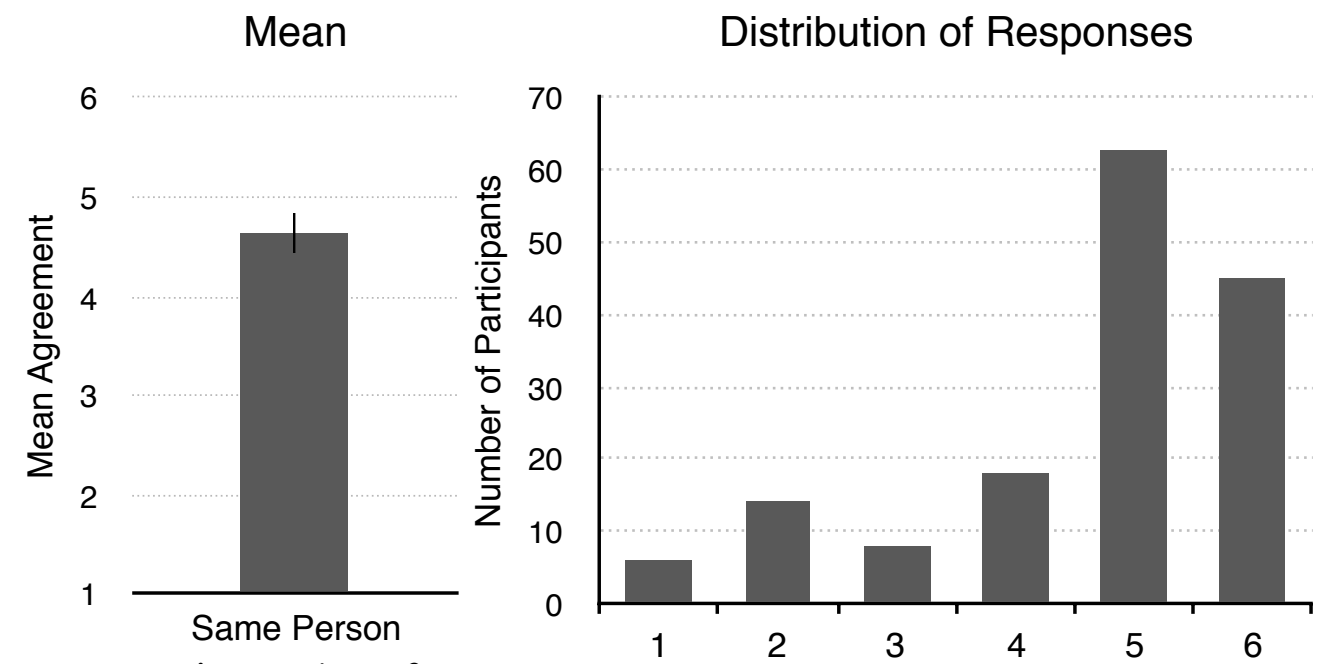

Figure 5. Experiment 4. Left Panel: mean agreement with the statement, "I ine same person retrieved the shirt and the pants." Error bar shows 95\% confidence interval. Right Panel: distribution of responses to the same statement. The scale ran 1 (strongly disagree) - 6 (strongly agree). Each panel collapses across condition (second/hour/week).

\section{Discussion}

These results replicate and further generalize the findings from Experiments 1-3. Most participants agreed that Derek recovered objects on different planets at the same time. Moreover, the same basic pattern emerged regardless of whether simultaneous co-location lasted a second, an hour, or even a week.

\section{Experiment 5: Physical Change}

The results thus far suggest that people do not follow the one-person-one-place rule when making judgments of personal identity, and that this pattern persists even when simultaneous colocation continues for an extended period of time. Nevertheless, people might balk at co-location 
if different bodily changes occur at each location. For example, although people might think that Derek can exist simultaneously on Venus and Mars for a week, they might deny that Derek continues to exist in both places when, during that time, five pounds is gained on Venus whereas five pounds is lost on Mars. The present experiment tested this possibility by presenting participants with cases involving weight gain and loss occurring over the course of a week in the two locations.

\section{Method}

Participants. One hundred new participants were tested (aged 18-63 years, mean age $=34$ years; 97\% reporting English as a native language; 41 female).

Materials and Procedure. Participants were randomly assigned to one of two conditions (Offset, Gain) in a between-subjects design. Each participant read a single story about a man, Derek, similar to the story used for the Clothes condition in Experiment 3. The key difference this time is that the stories for the different conditions varied whether weight was gained or lost on Venus and Mars. In the story for the Offset condition, the man who emerges from the transporter on Venus hangs around for a week and gains five pounds, while the man on Mars loses five pounds. In the story for the Gain condition, the man in each place gains five pounds. The full text of the story is included in the Appendix. After reading the story, participants answered the same questions as in Experiment 4. 


\section{Results}

Assignment to condition did not affect which option participants selected as best describing the situation, $\chi^{2}(3,100)=5.75, \mathrm{p}=.125$. Overall most participants $(77 \%)$ said that the best description was that Derek recovered the object on Venus and the object on Mars. (See Figure 6.) A small minority (15\%) said that someone else recovered both objects. Assignment to condition did not affect how frequently participants placed Derek on both Mars and Venus (i.e. answered "yes" for both the "Mars" and "Venus" options), $\chi^{2}(1,100)<.01, p=1$. Overall eighty-eight participants (88\%) placed Derek on both Mars and Venus. Assignment to condition did not affect mean agreement with the statement, "The same person retrieved the shirt and the pants," $t(98)=$ $-0.75, \mathrm{p}=.453$. Overall mean agreement $(\mathrm{M}=4.42, \mathrm{SD}=1.48)$ was significantly above the neutral midpoint, $\mathrm{t}(99)=6.22, \mathrm{p}<.001, \mathrm{~d}=0.62$, test value $=3.5$. (See Figure 7.) Most participants (78\%) agreed with this statement to at least some extent. 

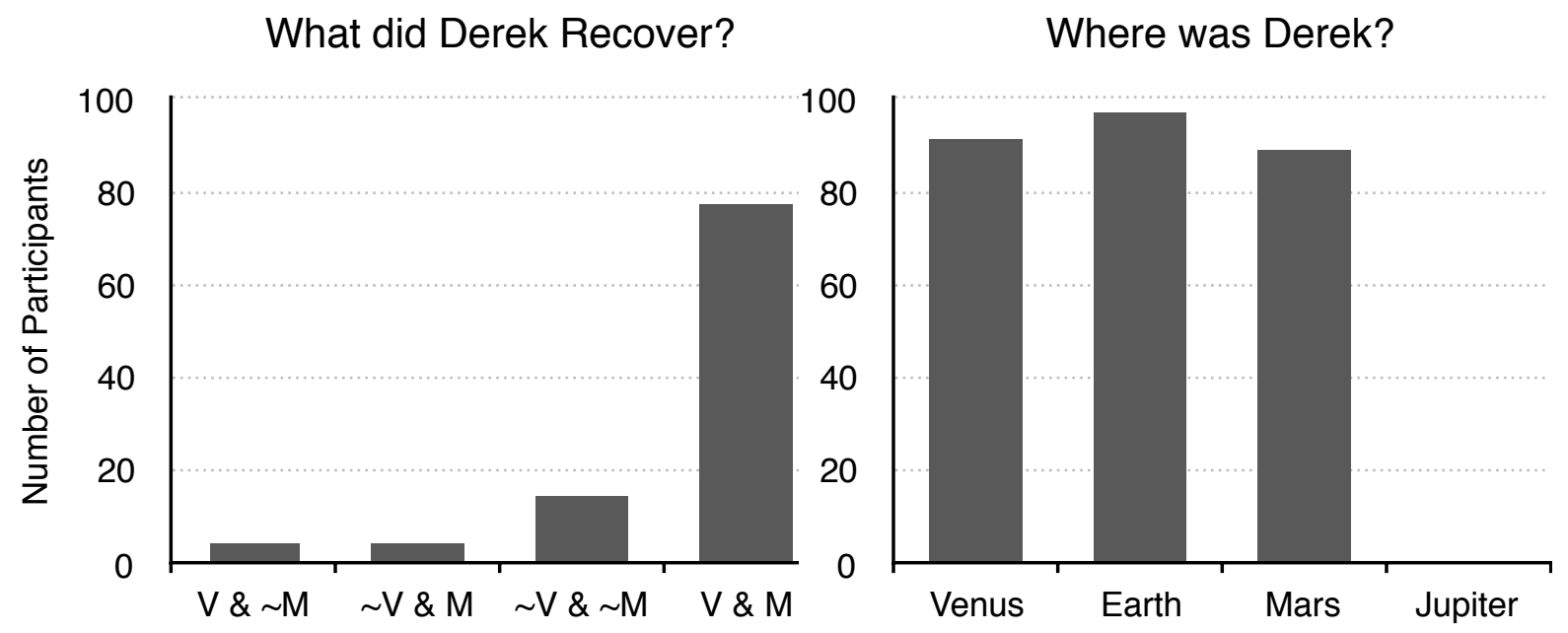

Figure 6. Experiment 5. Left Panel: the number of participants who selected each of the four options as the best description of what happened in the story. $\mathrm{V} \& \sim \mathrm{M}$ : Derek recovered the object on Venus but someone else recovered the object on Mars. $\sim V \&$ M: Derek recovered the object on Mars but someone else recovered the object on Venus. $\sim \mathrm{V} \& \sim \mathrm{M}$ : Someone else recovered the object on Venus and on Mars. V \& M: Derek recovered the object on Venus and on Mars. Right Panel: The number of participants placing Derek in the various locations at some point in the story. Each panel collapses across condition (offset/gain).
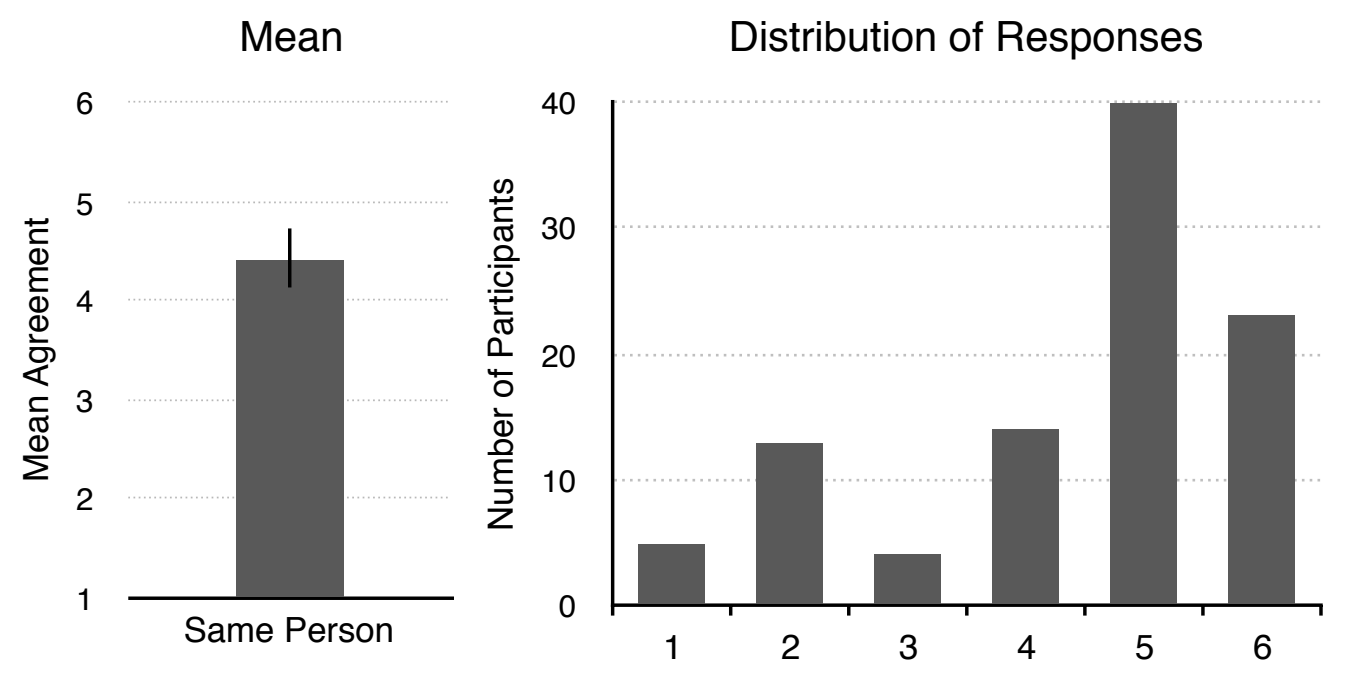

Figure 7. Experiment 5. Left Panel: mean agreement with the statement, "The same person retrieved the shirt and the pants." Error bar shows 95\% confidence interval. Right Panel: distribution of responses to the same statement. The scale ran 1 (strongly disagree) - 6 (strongly agree). Each panel collapses across condition (offset/gain). 


\section{Discussion}

These results replicate and further generalize the basic finding from earlier experiments. Most participants agreed that Derek recovered objects on different planets at the same time. Moreover, the same basic pattern emerged regardless of whether Derek simultaneously underwent significantly different physical changes on the different planets.

\section{Experiment 6: Shorter with Explicit Time-indexing}

Two concerns might be raised about all the teletransportation experiments thus far. First, participants read long and complex scenarios, so perhaps the results were due to participants becoming confused or bored. Second, perhaps the timing of the teletransportation events was insufficiently clear. This final experiment tested these concerns by presenting participants with much shorter and simpler stories that included clear and explicit time-indexing.

\section{Method}

Participants. One hundred new participants were tested (aged 19-65 years, mean age $=35$ years; 93\% reporting English as a native language; 39 female)

Materials and Procedure. Participants were randomly assigned to one of two conditions (Single, Double) in a between-subjects design. The stories used for the conditions were similar to those used in Experiments 1 and 4, with the notable features being that they were much shorter 
and included explicit time-indexing. The full text of the story is included in the Appendix. After reading the story, participants answered the same questions as in Experiment 4.

\section{Results}

Assignment to condition affected which option participants selected as best describing the situation, $\chi^{2}(3,100)=74.83, p<.001$, Cramer's $V=.865$. (See Figure 8.) Most participants in the Single condition (85\%) said that the best description was that Derek recovered the object on Venus but someone else recovered the object on Mars. Most participants in the Double condition (70\%) said that the best description was that Derek recovered the object on Venus and on Mars. Assignment to condition also affected how frequently participants placed Derek on both Mars and Venus (i.e. answered "yes" for both the "Mars" and "Venus" options), $\chi^{2}(1,100)=35.41, \mathrm{p}<$ .001 , Cramer's $V=.595$. In the Single condition ten participants $(19 \%)$ placed Derek in both locations, whereas in the Double condition thirty-eight participants (79\%) did so. Assignment to condition did not affect mean agreement with the statement, "The same person retrieved the shirt and the pants," $t(98)=-13.35, \mathrm{p}<.001, \mathrm{~d}=2.70$. (See Figure 9.) Participants in the Single condition tended to disagree with the statement $(M=1.71, S D=1.19), t(51)=-10.80, p<.001, d$ $=1.50$, test value $=3.5$; participants in the Double condition tended to agree with it $(\mathrm{M}=4.81$, $\mathrm{SD}=1.12), \mathrm{t}(47)=8.10, \mathrm{p}<.001, \mathrm{~d}=1.17$, test value $=3.5$. Very few participants in the Single condition $(8 \%)$ agreed with the statement to at least some extent, whereas most participants in the Double condition ( $88 \%$ ) did so. 

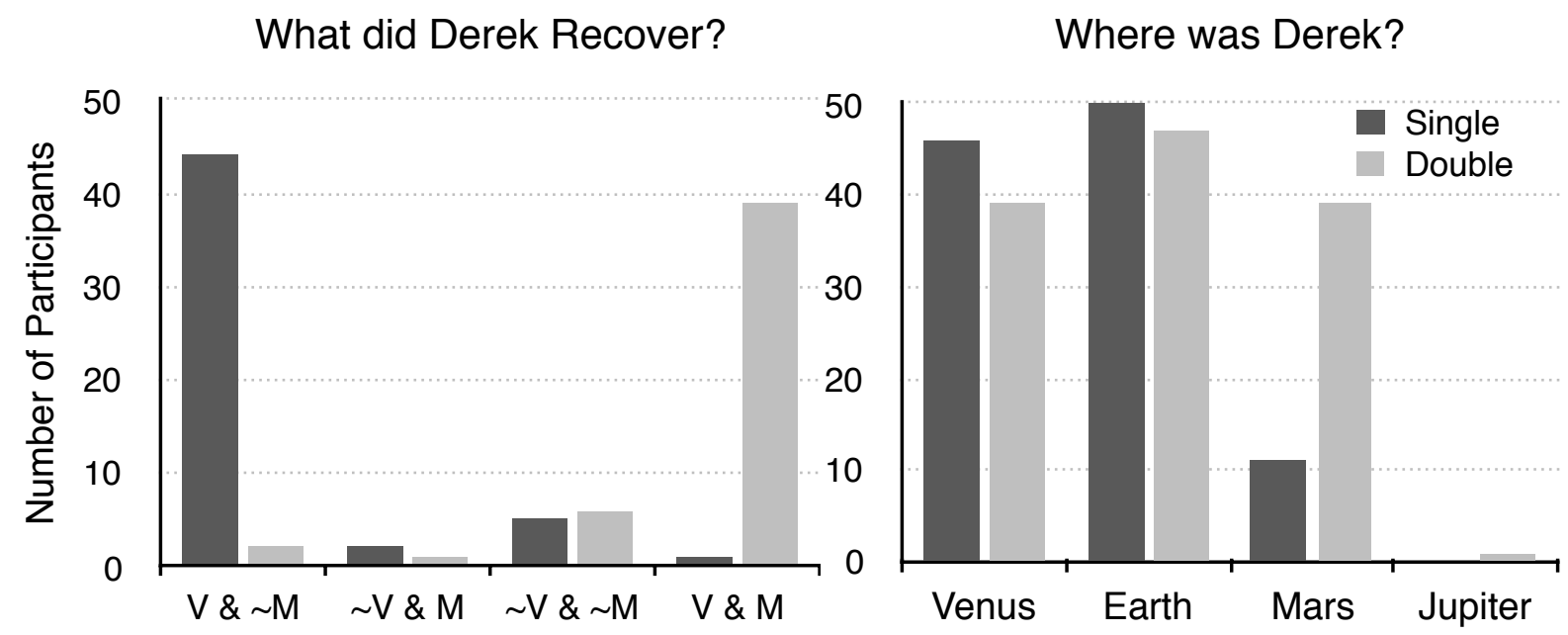

Figure 8. Experiment 6. Left Panel: the number of participants who selected each of the four options as the best description of what happened in the story. $\mathrm{V} \& \sim \mathrm{M}$ : Derek recovered the object on Venus but someone else recovered the object on Mars. $\sim V \&$ M: Derek recovered the object on Mars but someone else recovered the object on Venus. $\sim \mathrm{V} \& \sim \mathrm{M}$ : Someone else recovered the object on Venus and on Mars. V \& M: Derek recovered the object on Venus and on Mars. Right Panel: The number of participants by condition who answered that Derek's was in the various locations at some point in the story. 

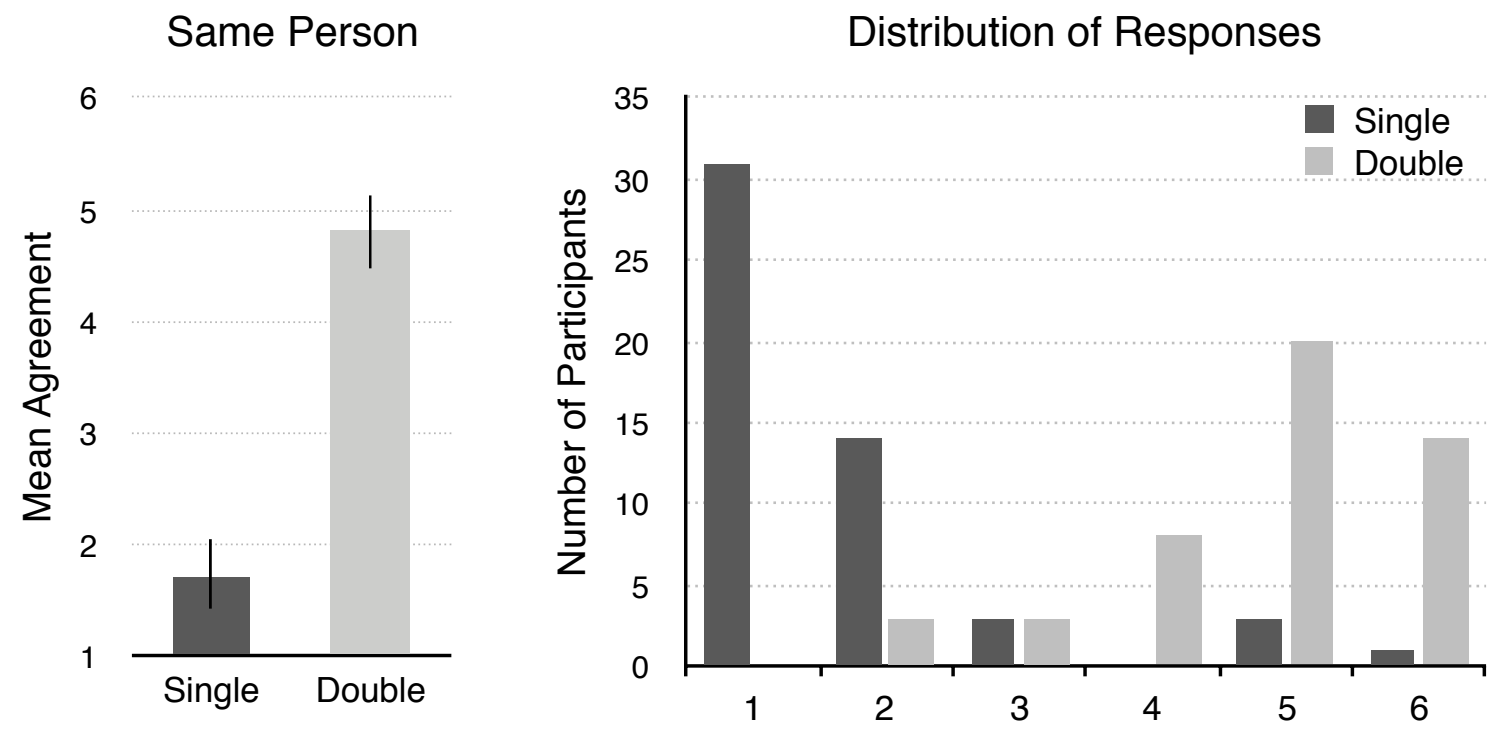

Figure 9. Experiment 6. Left Panel: mean agreement with the statement, "The same person retrieved the shirt and the pants." Error bars show 95\% confidence intervals. Right Panel: distribution of responses to the same statement. The scale ran 1 (strongly disagree) - 6 (strongly agree).

\section{Discussion}

These results replicate and further generalize the basic finding from earlier experiments. In a double-teletransportation case, most participants agreed that Derek recovered objects on different planets at the same time, whereas most disagreed with this in a closely matched singleteletransportation case. Moreover, we observed this pattern with stimuli that were much shorter and simpler than in earlier experiments, and which also included clear and explicit time-indexing for all the teletransportation events.

\section{Conclusion}

Across six experiments, we studied people's judgments about personal identity. The main finding 
was that these judgments do not follow the one-person-one-place rule. In a case involving multiple teletransportation of an agent, participants judged that one and the same individual was on two different planets at the same time (Experiment 1). We replicated this same basic finding while varying a number of potentially important factors. In a case involving transplantation of both halves of an agent's brain into two new bodies, participants judged that one and the same individual was in two separate rooms at the same time (Experiment 2). We also replicated the finding with stimuli that lacked social cues and important personal relationships (Experiment 3), in cases where multiple co-location lasted a week (Experiment 4), in cases where the person simultaneously underwent significantly different bodily changes in the two locations (Experiment 5), and with simplified stimuli that included explicit time-indexing for all teletransportation events (Experiment 6).

Taken together, these findings show for the first time that judgments of personal identity allow for one person to be in two different places simultaneously, and that this allowance is robust against a number of noteworthy manipulations. In light of recent findings on identity judgments about material objects and non-human animals (see the Introduction for references and discussion), our results suggest that personal identity judgments are surprisingly similar to other sorts of identity judgments. In multiple domains, identity judgments do not appear to follow a one-object-one-place rule. One interesting theoretical possibility, then, is that personal identity judgments recruit more basic criteria used to re-identify individual things and apply them to the domain of persons. 
Our findings are relevant to philosophical debates focused on the "logic" or "criteria" of ordinary judgments of personal identity. To take the most obvious example, a widely held view is that we are absolutely committed to the one-person-one-place rule, according to which one person cannot be in two different places at the same time (e.g. Williams 1960; Chisholm 1970; Garrett 2002; Beck 2006). The findings also suggest that other claims made by philosophers have been unduly neglected. For example, consider Parfit's math-exam case, of which Parfit said it is not absurd to think that one mind could be divided into two streams of consciousness and then reunited (Parfit 1971). Parfit claimed that according to the ordinary concept of personal identity, in this case, one and the same person has two separate sets of experiences. Nevertheless, Parfit denied that this same judgment extends to prolonged cases involving separate bodies at different locations. When multiple bodies are involved, Parfit claimed, it becomes "intolerable" to say that one person is in both locations (Parfit 1971: 7). However, our results suggest that exactly the opposite is true: according to the criteria we actually use, the same verdict does extend to prolonged cases involving separate bodies. In this way, our results can fruitfully inform philosophical debates aimed at identifying "the criteria of personal identity that we actually use" (Parfit 1971: 3; see also Parfit 1995: 15, 41).

A natural question is why philosophers might have thought that the one-person-one-place rule was intuitive in the first place. Our studies were not designed to answer this question, so we can only speculate about the answer. We are unaware of any research estimating what proportion of philosophers find the one-person-one-place rule intuitive, but we do not deny that some 
philosophers find this rule intuitive. This becomes clear when we look at the language philosophers have used to describe cases like the double transporter or the double brain transplantation case. For instance, Chisholm assumes that "there is no possibility whatever that you would be both the person on the right and the person on the left" (Chisholm 1997: 229). Recall also Parfit's suggestion that it would be "intolerable" to claim that "two bodies" that "could live at opposite ends of the earth" are the same person (Parfit 1971: 1; see also Shoemaker \& Swinburne 1984). However, our results show that this is not how such cases are naturally judged. Consistent with our findings, there might be good reasons for abandoning the ordinary personal identity concept and adopting a new one that incorporates the one-person-oneplace rule. Future work could assess the merits and demerits of such prescriptive proposals.

Establishing that ordinary judgments about personal identity are not constrained by the one-person-one-place rule is an exciting first step in understanding the ordinary concept of personal identity. However, more work is required to uncover the concept's precise nature and limits. Although our results provide evidence that the one-person-one-place rule is not part of the ordinary "logic" of personal identity, they do not show that considerations of simultaneous colocation are completely irrelevant. Consistent with our findings, people might be less comfortable attributing location in two places than in one place. There are many possible explanations for why this would be the case, including low-level explanations in terms of lower confidence due to unfamiliarity with actual examples of co-location.

Future work could test the limits of simultaneous co-location. Most people accept that 
one and the same person can be in two places at once. Indeed, most people accepted that a person could exist in two places for an extended period of time, up to at least one week (Experiment 4). But presumably there is a limit to this. Can one person be in five, ten, or a hundred places once, even if only for a brief instant? Or, what if one person persisted in two places for decades, or while undergoing radically different bodily transformations in each location?

Relatedly, could one person exist in two different places while undergoing different psychological changes, such as developing different preferences, beliefs, and memories? Much philosophical scholarship has discussed the importance of psychological factors in the ordinary concept of identity (e.g. Locke 1689; Shoemaker 1970; Parfit 1971; Perry 1975; Lewis 1976; Noonan 1989; Unger 1990). Perhaps drastic psychological change across co-located figures would lead people to judge that the figures, such as those in the double conditions in our experiments, are different persons. While this sort of experiment would no doubt be worthwhile, it extends beyond the scope of the present investigation. Properly testing this possibility would require assessing the extent to which people think that significant psychological change affects identity even in singular cases. For instance, if people think Derek at a later time is a "different person" than Derek at an earlier time because of drastic psychological change, this judgment would be a confound for testing psychological change over time in conjunction with multiple colocation.

Future work could also investigate whether we are committed to other rules when judging personal identity. For instance, are we committed to a one-place-one-person rule, according to 
which no more than one person can occupy a place at once? The answer to this question would further elucidate the ordinary concept of personal identity. It could also have practical implications. For instance, it could affect how people judge psychiatric diagnoses of multiple personalities, thereby affecting social supports for people struggling with such a condition.

Acknowledgments - For helpful discussion and feedback, we thank Teresa Branch-Smith, Wesley Buckwalter, Jacob Dink, Mathieu Doucet, Ori Friedman, Ashley Keefner, Nick Leonard, Janet Michaud, J. Charles Millar, Shaylene Nancekivell, Madison Pesowski, Lance Rips, Christina Starmans, Nina Strohminger, Polly Summers, and Angelo Turri. Thanks also to an audience at the 2014 Buffalo Experimental Philosophy Conference and the editors and referees of this volume. This research was supported by the Social Sciences and Humanities Research Council of Canada, the Ontario Ministry of Economic Development and Innovation, and the Canada Research Chairs program.

\section{References}

Chisholm, R. (1970). Reply to Strawson's comments. In H. E. Kiefer and Milton K. Munitz (eds.), Language, belief, and metaphysics. Albany, NY: SUNY Press, 187-189.

Chisholm, R. (1997). Identity through time. In Michael C. Rea (ed,), Material Constitution: A Reader. Oxford: Rowman and Littlefield, 209-235. 
DeGrazia, D. (2003). Identity, killing, and the boundaries of our existence. Philosophy and Public Affairs, 31(4), 413-442.

Fodor, J. A. (1964). On knowing what we would say. The Philosophical Review, 198-212.

Garrett, B. (2002). Personal identity and self-consciousness. New York: Routledge.

Gendler, T. S. (2002). Personal identity and thought-experiments. The Philosophical Quarterly, 52(206), 34-54. doi:10.1111/1467-9213.00251.

Hood, B., Gjersoe, N. L., \& Bloom, P. (2012). Do children think that duplicating the body also duplicates the mind? Cognition, 125(3), 466-474. doi:10.1016/j.cognition.2012.07.005

Lewis, D. (1976). Survival and identity. In A. Rorty (ed.), The Identities of Persons, Berkeley, CA: University of California Press; reprinted in his Philosophical Papers vol. I, New York: Oxford University Press, 1983.

Locke, J. (1689/1975). An essay concerning human understanding. (P. H. Nidditch, ed.). Oxford: Clarendon Press.

McMahan, J. (2002). The ethics of killing: problems at the margins of life. Oxford University Press.

Nichols, S. and Bruno, M. (2010). Intuitions about personal identity: An empirical study. Philosophical Psychology 23 (3):293-312.

Noonan, H. (1989). Personal Identity. London: Routledge

Olson, E. T. (1997). Was I ever a fetus? Philosophy and Phenomenological Research, 57(1), 95-110. 
Olson E. (2010). Personal identity. The Stanford Encyclopedia of Philosophy (Winter 2010 Edition), Zalta, E. N.(ed.), URL $=<$ http://plato.stanford.edu/archives/win2010/entries/ identity-personal/>.

Perry, J. (1975). Personal identity. Berkeley: University of California Press.

Parfit, D. (1971). Personal identity. The Philosophical Review, 80(1), 3-27.

Parfit, D. (1984). Reasons and persons. Oxford University Press.

Parfit, D. (1995). The unimportance of idenity. In H. Harris (Ed.), Identity. Oxford University Press, 13-45.

Rips, L. J., Blok, S., and Newman, G. (2006). Tracing the identity of objects. Psychological Review, 113(1), 1.

Rips, L. J. (2011). Split identity: intransitive judgments of the identity of objects. Cognition, 119(3), 356-373.

Shoemaker, S. (1970). Persons and their pasts. American Philosophical Quarterly, 7, 269-285.

Shoemaker, S., and Strawson, G. (1999). Self and body. Proceedings of the Aristotelian Society, Supplementary Volumes, 287-332.

Shoemaker, S. and R. Swinburne (1984). Personal identity, Oxford: Basil Blackwell.

Soltis, J., Leong, K., \& Savage, A. (2005). African elephant vocal communication I: antiphonal calling behaviour among affiliated females. Animal Behaviour, 70(3), 579-587. doi: 10.1016/j.anbehav.2004.11.015

Strohminger, N., and Nichols, S. (2014). The essential moral self. Cognition, 131, 151-179. 
Unger, P. (1990). Identity, consciousness, and value. Oxford: Oxford University Press.

Wiggins, D. (1967). Identity and spatio-temporal continuity. Oxford, Blackwell.

Wilkes, K. V., \& Wilkes. (1988). Real people: personal identity without thought experiments. Oxford: Clarendon Press.

Williams, B. A. O. (1960). Bodily continuity and personal identity: a reply. Analysis, 21(2), $43-48$.

Williams, B. A. O. (1970). The self and the future. The Philosophical Review, 161-180.

\section{Appendix}

\section{Experiment 1}

[Single/Double] The year is 2450 and human civilization has advanced so far that we could barely comprehend it. Derek is currently on Earth. His wife is on Venus. His mother is on Mars. $q^{2}$ Feeling somewhat lonely, Derek enters the Quantum Teletransporter in his house on Earth and says, "I want to visit my wife and I want to [visit her now/visit my mother]." Then he presses the button. In an instant, the quantum device scans his body and records the exact state of all his cells and brain states. Instantly, the information travels through an information wormhole to Venus and [Venus alone/also to Mars], where it is perfectly reconstituted in physical form. I Instantly, a figure steps out of the Teletransporter in Derek's wife's apartment on Venus. With a

2 Indicates a paragraph break on the participant's screen. 
smile, they hug and she says, "My dear! I'm so happy to see you!" " Simultaneously [a delivery person knocks on the door of Derek's mother's apartment on Mars. With a smile, she hugs her and says, "My medication! I'm so happy to receive it!" / a figure steps out of the Teletransporter in Derek's mother's apartment on Mars. With a smile, they hug and she says, "My dear! I'm so happy to see you!’] ๆ Derek’s house on Earth is now empty.

\section{Experiment 2}

[Single/Double] The year is 2450 and human civilization has advanced so far that we could barely comprehend it. Derek, a young man in the prime of life, was recently diagnosed with an incurable wasting condition in his body. But his brain is perfectly fine, so doctors recommend growing [a new body/two new bodies] to host Derek's consciousness. The host [body is/bodies are] grown from Derek's own stem cells, so [it/they] perfectly [matches/match] Derek's DNA and physical stature. If Doctors first reorganize the information in Derek's brain so that all memories, emotions, and traits are redundantly duplicated in each half of the brain (just like two hard drives kept in perfect sync). After administering a sedative, one team of doctors carefully removes one half of Derek's brain and carefully implants it into the new body, which is then wheeled to the West Recovery Room. I Simultaneously, another team of doctors carefully implants the other half of Derek's brain into [a preservation tank and saves it as a backup, which is kept ready in the operating room/the other new body, which is then wheeled to the East Recovery Room.] ๆ Derek's wife is waiting anxiously in the West Recovery Room. As she sits 
near the new body, to her delight she hears a familiar voice say, "Dear, it's great to see you." The two hug and she says, "My dear husband! I am so happy to see you!" " Derek's mother is waiting anxiously in the East Recovery Room. As she sits near the [coffee machine/new body], to her delight she hears a familiar voice say, [“Grandma, I'm here to see you/Mom, it's great to see you." The two hug and she says, "My dear [granddaughter/son]! I am so happy to see you [too]!" T The operating room is now empty.

\section{Experiment 3}

[Clothes/Children] The year is 2450 and human civilization has advanced so far that we could barely comprehend it. Derek is a 6-foot, 200-pound man currently on Earth. His [favorite shirt is hanging/infant daughter is being babysat] in his apartment on Venus. His [favorite pair of pants is hanging/infant son is being babysat] in his apartment on Mars. I Derek wants to [wear his favorite outfit/bring his children] to a family reunion later that day. So he enters the Quantum Teletransporter in his house on Earth and says, "I want to visit my apartment on Venus and I want to visit my apartment on Mars." Then he presses the button. In an instant, the quantum device scans his body and records the exact state of all his cells and brain states. Instantly, the information travels through an information wormhole to Venus and also to Mars, where it is perfectly reconstituted in physical form. II Instantly, a 6-foot, 200-pound man steps out of the Teletransporter in Derek's apartment on Venus. With his left hand, he retrieves the [shirt hanging there/infant girl], steps back into the Teletransporter, and says, "Take me to the house on Earth." 
I Simultaneously, a 6-foot, 200-pound man steps out of the Teletransporter in Derek's apartment on Mars. With his right hand, he retrieves the [pants hanging there/infant boy], steps back into the Teletransporter, and says, "Take me to the house on Earth." " An instant later, a 6-foot, 200pound man emerges from the Teletransporter in Derek's house on Earth. He is holding [a shirt/an infant girl] in his left hand, and [pants/an infant boy] in his right hand.

\section{Experiment 4}

[Second/Hour/Week] The year is 2450 and human civilization has advanced so far that we could barely comprehend it. Derek is a 6-foot, 200-pound man currently on Earth. His favorite shirt is hanging in his apartment on Venus. His favorite pair of pants is hanging in his apartment on Mars. ๆ Derek wants to wear his favorite outfit to a family reunion [this afternoon/next month/ next month]. So he enters the Quantum Teletransporter in his house on Earth and says, "I want to visit my apartment on Venus and I want to visit my apartment on Mars." Then he presses the button. In an instant, the quantum device scans his body and records the exact state of all his cells and brain states. Instantly, the information travels through an information wormhole to Venus and also to Mars, where it is perfectly reconstituted in physical form. I Instantly, a 6-foot, 200-pound man steps out of the Teletransporter in Derek's apartment on Venus. He rests for exactly one [second/hour/week] because he is so [hurried/tired/tired]. Then, with his left hand, he retrieves the shirt hanging there, steps back into the Teletransporter, and says, "Take me to the house on Earth." I Simultaneously, a 6-foot, 200-pound man steps out of the Teletransporter in 
Derek's apartment on Mars. He rests for exactly one [second/hour/week] because he is so [hurried/tired/tired]. Then, with his right hand, he retrieves the pants hanging there, steps back into the Teletransporter, and says, "Take me to the house on Earth." " An instant later, a 6-foot, 200-pound man appears in the Teletransporter in Derek's house on Earth. He is holding a shirt in his left hand, and pants in his right hand.

\section{Experiment 5}

[Offset/Gain] Transport The year is 2450 and human civilization has advanced so far that we could barely comprehend it. Derek is a 6-foot, 200-pound man currently on Earth. His favorite shirt is hanging in his apartment on Venus. His favorite pair of pants is hanging in his apartment on Mars. ๆ Derek wants to wear his favorite outfit to a family reunion next month. So he enters the Quantum Teletransporter in his house on Earth and says, "I want to visit my apartment on Venus and I want to visit my apartment on Mars." Then he presses the button. In an instant, the quantum device scans his body and records the exact state of all his cells and brain states. Instantly, the information travels through an information wormhole to Venus and also to Mars, where it is perfectly reconstituted in physical form. I Instantly, a 6-foot, 200-pound man steps out of the Teletransporter in Derek's apartment on Venus. He rests for exactly one week because he is so tired. During this time, he gains 5 pounds. Then, with his left hand, he retrieves the shirt hanging there, steps back into the Teletransporter, and says, "Take me to the house on Earth." I Instantly, a 6-foot, 200-pound man steps out of the Teletransporter in Derek's apartment on Mars. 
He rests for exactly one week because he is so tired. During this time, he [loses/gains] 5 pounds. Then, with his left hand, he retrieves the pants hanging there, steps back into the Teletransporter, and says, "Take me to the house on Earth." I An instant later, a 6-foot, [200/205]-pound man appears in the Teletransporter in Derek's house on Earth. He is holding a shirt in his left hand, and pants in his right hand.

\section{Experiment 6}

[Single] The year is 2450. Derek is a 6-foot, 200-pound man on Earth. Derek wants to wear his favorite outfit to a family reunion later today. But he left his shirt on Venus and his pants on Mars. So, at exactly 2:00 pm, he enters the Quantum Teletransporter in his house on Earth and says, "I want to visit my apartment on Venus and notify the staff in my apartment on Mars." q At exactly 2:01 pm, a 6-foot, 200-pound man steps out of the Teletransporter in Derek's apartment on Venus. With his left hand, he retrieves the shirt hanging there, steps back into the Teletransporter, and says, "Take me to the house on Earth." " Also at exactly 2:01 pm, a 5-foot, 120-pound maid receives a message in Derek's apartment on Mars. With her right hand, she retrieves the pants hanging there, steps into the Teletransporter, and says, "Take me to the house on Earth." I At exactly 2:02 pm, a 6-foot, 200-pound man appears in the Teletransporter in Derek's house on Earth. He is holding a shirt in his left hand. And a 5-foot, 120-pound maid also appears. She is holding pants in her right hand.

[Double] The year is 2450. Derek is a 6-foot, 200-pound man on Earth. Derek wants to 
wear his favorite outfit to a family reunion later today. But he left his shirt on Venus and his pants on Mars. So, at exactly 2:00 pm, he enters the Quantum Teletransporter in his house on Earth and says, "I want to visit my apartment on Venus and I want to visit my apartment on Mars." At exactly 2:01 pm, a 6-foot, 200-pound man steps out of the Teletransporter in Derek's apartment on Venus. With his left hand, he retrieves the shirt hanging there, steps back into the Teletransporter, and says, "Take me to the house on Earth." " Also at exactly 2:01 pm, a 6-foot, 200-pound man steps out of the Teletransporter in Derek's apartment on Mars. With his right hand, he retrieves the pants hanging there, steps back into the Teletransporter, and says, "Take me to the house on Earth." I At exactly 2:02 pm, a 6-foot, 200-pound man appears in the Teletransporter in Derek's house on Earth. He is holding a shirt in his left hand, and pants in his right hand. 